\title{
Subarachnoid Haemorrhage after Stereotactic Catheterization of Intracerebral Hematoma
}

\section{Seong Hoon Jeong and Hyo Joon Kim}

Department of Neurosurgery, Presbyterian Medical Center, College of Medicine, Seonam University, Korea

"Corresponding author: Hyo Joon Kim, Department of Neurosurgery, Presbyterian Medical Center, College of Medicine, Seonam University, Korea, Tel: +82-63-230-8667, Fax: +82-63-230-8129; E-mail: hj-kim@hanmail.net

Rec date: Aug 04, 2016; Acc date: Aug 22, 2016; Pub date: Aug 24, 2016

Copyright: (c) 2016 Jeong SH, et al. This is an open-access article distributed under the terms of the Creative Commons Attribution License, which permits unrestricted use, distribution, and reproduction in any medium, provided the original author and source are credited.

\begin{abstract}
The authors report the complication that occurred after stereotactic catheterization in a 71-year-old patient with a spontaneous intracerebral hematoma $(\mathrm{ICH})$. After stereotactic catheterization, a subarachnoid haemorrhage $(\mathrm{SAH})$ was found in the post-operative CT scan. An SAH is a rare complication related with stereotactic catheterization. We investigated the cause and reported about a newly occurring SAH after stereotactic catheterization.
\end{abstract}

Keywords: Intracranial haemorrhage; Stereotactic techniques; Hematoma; Complication

\section{Introduction}

Blood pressure control [1], hemostatic therapy [2], Intracranial pressure (ICP) control [3], anti-convulsant therapy [4], and blood glucose control [5] are needed to treat intracerebral hematoma (ICH). In addition, neurosurgical operation may be considered depending on mental state, the location and amount of the hemorrhage, and neurological symptoms.

There are several surgery methods such as craniotomy, burr hole aspiration and stereotactic aspiration. Among such surgical modalities, stereotactic aspiration is the least invasive and most effective surgery for ICH patients. Stereotactic aspiration requires only a short operation under local anaesthesia, and there is little risk of damage to normal brain tissue [6]. Furthermore, catheters can be inserted precisely into the hematoma. However, they can cause complications, such as rebleeding, infection, epidural hematoma, and neurological symptoms. The purpose of this case study is to report the cause of a subarachonoid hemorrhage (SAH) after stereotactic aspiration.

\section{Case Study}

This 71-year-old patient came to the hospital due to mental deterioration and left side weakness. His score on the Glasgow Coma Scale (GCS) was 12 points, and his left side extremities showed hemiparesis with a poor motor grade. He had smoked for 25 years and he had been treated for prostatic cancer one year ago. In addition, he had been admitted to the hospital due to infarction and hypertension, and he was still taking anti-hypertension medicines.

On brain CT, there was an almost $25 \mathrm{ml} \mathrm{ICH}$ on the right basal gangilia. Stereotactic aspiration using a Leksell stereotactic frame was planned via the shortest approach (i.e., through the temporal area). Coordination was calculated with Surgiplan (Elekta, Stockholm, Sweden). Local anesthesia was done with lidocaine. Then, a bur hole was made for catheter passage, and through a 7-Fr silicon catheter, a roughly $5 \mathrm{ml}$ blood clot was extracted and the catheter was fixed on the scalp.
On post-operative CT, a newly occurring SAH (Fisher grade 3) was found (Figure 1).

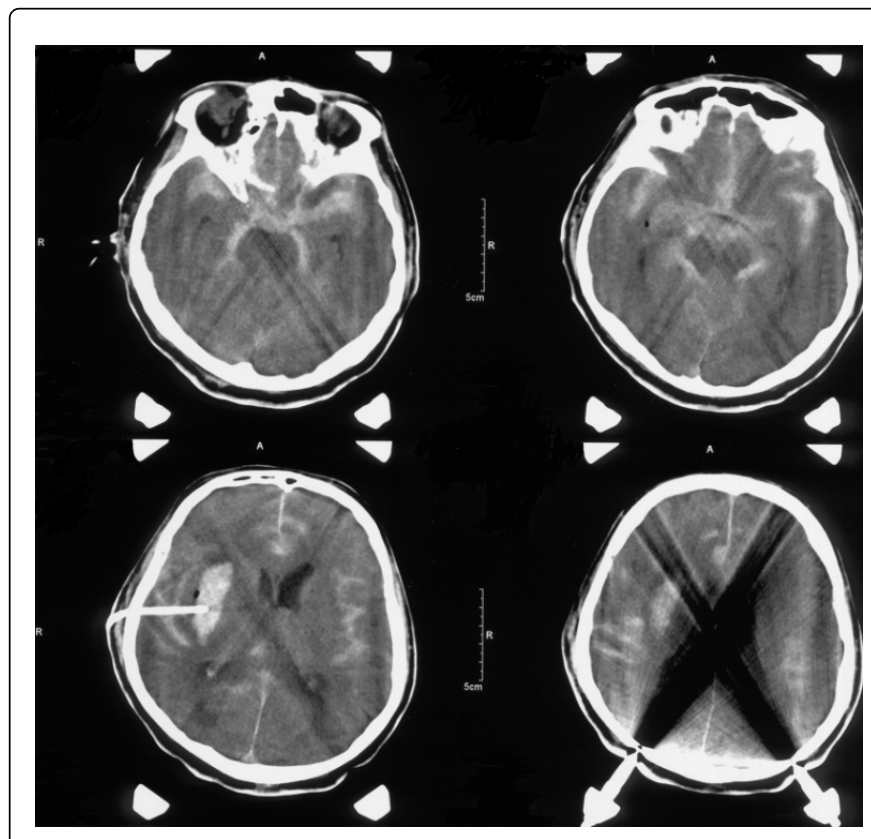

Figure 1: Immediate post-operative brain CT. The patient had a spontaneous ICH and was treated with stereotactic aspiration. In the post-operative brain CT scan, a newly occurring SAH (Fisher grade 3) was found. In addition, the silicon catheter was inserted into the middle of the hematoma.

We tried to find any vascular abnormalities by transfemoral cerebral angiography, but there were no remarkable abnormalities. We only found that there was a cortical vein in the course of the inserted catheter (Figure 2). 


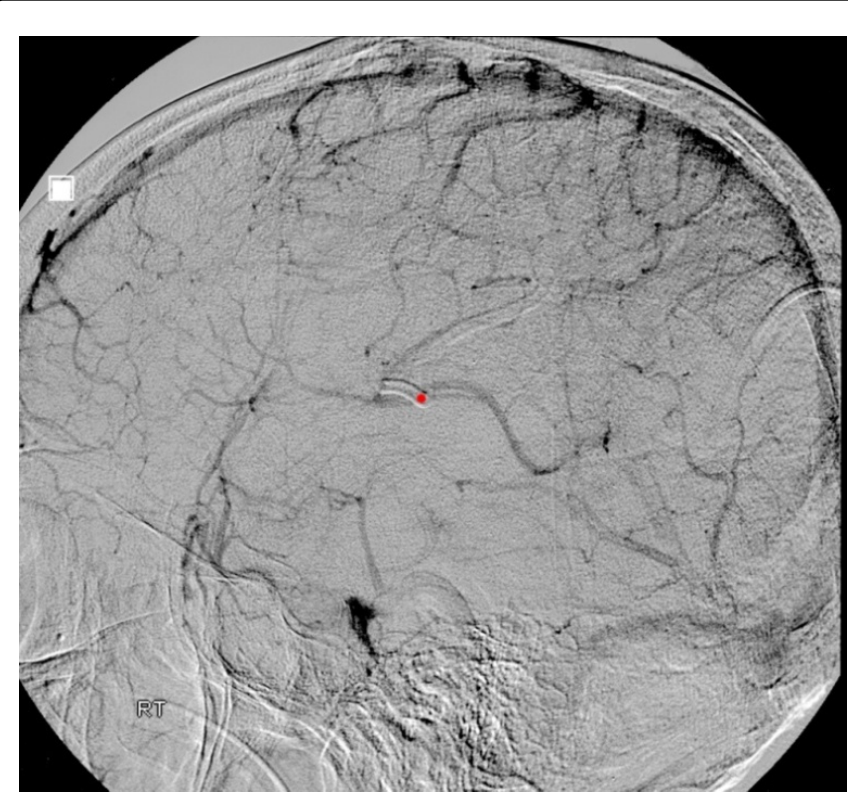

Figure 2: Cerebral angiography. To determine the cause of the newly occurring $\mathrm{SAH}$, trans femoral cerebral angiography was performed. The catheter was inserted into cortical vein (red spot).

Therefore, we suspected that cortical vein injury during stereotactic aspiration caused the SAH. The catheter was kept in place as it was. Because the ICH and SAH were reduced on the following brain CT, the catheter was removed after two weeks after checking almost all of the ICH and SAH had been absorbed. In the third week following the CT, there was no remnant ICH or SAH and the patient's mental status was improved with a GCS score of 13.

\section{Discussion}

According to Fujitsu, there are some indications for operation such as a hematoma larger than $3 \mathrm{~cm}$, a GCS score of 6-12, and neurological deterioration [7]. Moreover beginning the operation less than 6 hours from the occurrence of the ICH can cause re-bleeding because of the low compressive pressure of bleeding [8-11].

Generally, in the case of lobar, shallow ICH, craniotomy could be considered, but in the case of cortical or deep-seated ICH, stereotactic aspiration reduces brain tissue damage and show a better prognosis than craniotomy $[6,12]$. Re-bleeding was seen in $7 \%$ of the 97 patients in Niizuma's study and $11 \%$ of the 569 patients in Kanaya's study $[13,14]$.

Since aneurysms or AVM were found in $48 \%$ of patients younger than 45 without hypertension, $49 \%$ of lobar ICH patients, and $65 \%$ of
Intraventricular hemorrhage(IVH) patients, preoperative angiography or planning with enhanced CT images might help to reduce vessel injury [8].

\section{Conclusion}

An SAH during the stereotactic aspiration of $\mathrm{ICH}$ is very rare. In this case, a cortical vein injury that occurred during catheter insertion was suspected to have caused the SAH.

\section{References}

1. Grossman E, Messerli FH, Grodzicki T, Kowey P (1996) Should a moratorium be placed on sublingual nifedipine capsules given for hypertensive emergencies and pseudoemergencies?. JAMA 276: 1328-1331.

2. Mayer SA, Brun NC, Begtrup K, Broderick J, Davis S, et al. (2005) Recombinant activated factor VII for acute intracerebral hemorrhage. $\mathrm{N}$ Engl J Med 352: 777-785.

3. Nilsson OG, Lindgren A, Brandt L, Saveland H (2002) Prediction of death in patients with primary intracerebral hemorrhage: a prospective study of a defined population. J Neurosurg 97: 531-536.

4. Qureshi AI, Tuhrim S, Broderick JP, Batjer HH, Hondo H, et al. (2001) Spontaneous intracerebral hemorrhage. N Engl J Med 344: 1450-1460.

5. Fogelholm R, Murros K, Rissanen A, Avikainen S (2005) Admission blood glucose and short term survival in primary intracerebral haemorrhage: a population based study. J Neurol Neurosurg Psychiatry 76: 349-353.

6. Fogelholm R, Murros K, Rissanen A, Avikainen S (2005) Long term survival after primary intracerebral haemorrhage: a retrospective population based study. J Neurol Neurosurg Psychiatry 76: 1534-1538.

7. Fujitsu K, Muramoto M, Ikeda Y, Inada Y, Kim I, et al. (1990) Indications for surgical treatment of putaminal hemorrhage. J Neurosurg 73: 518.

8. Ariesen MJ, Claus SP, Rinkel GJ, Algra A (2003) Risk factors for intracerebral hemorrhage in the general population: a systematic review. Stroke 34: 2060-2065.

9. Kanno T, Sano H, Shinomiya Y, Katada K, Nagata J, et al. (1984) Role of surgery in hypertensive intracerebral hematoma. A comparative study of 305 nonsurgical and 154 surgical cases. J Neurosurg 61: 1091-1099.

10. Kidwell CS, Chalela JA, Saver JL, Starkman S, Hill MD, et al. (2004) Comparison of MRI and CT for detection of acute intracerebral hemorrhage. JAMA 292: 1823-1830.

11. Park JY, Jung N, Shin MS, Park KW, Huh SK (1992) Result of stereotactic aspiration of spontaneous putaminal hematoma. J Korean Neurosurg Soc 21: $1045-1050$.

12. Zuccarello M, Andaluz N, Wagner KR (2002) Minimally invasive therapy for intracerebral hematomas. Neurosurg Clin N Am 13: 349-354.

13. Kaneko M, Tanaka K, Shimada T, Sato K, Uemura K (1983) Long-term evaluation of ultra-early operation for hypertensive intracerebral hemorrhage in 100 cases. J Neurosurg 58: 838-842.

14. Zhu XL, Chan MS, Poon WS (1997) Spontaneous intracranial hemorrhage: which patients need diagnostic cerebral angiography? A prospective study of 206 cases and review of the literature. Stroke 28: 1406-1409. 